An analysis of public policy issues and how they affect MRS members and the materials community...

\title{
Visibility Leads to Ensured Cut of the Pie
}

The following is an edited version of George E. Brown, Ir.'s presentation at the Federation of Materials Societies' 14th Biennial Conference on National Materials Policy.

The Federation of Materials Societies (FMS) is unique: Not many groups can claim to have entire ages of humanity named after their work. We have the Stone Age, the Bronze Age, and the Iron Age all named after the discovery and use of new materials. But these discoveries are coming at such a rapid rate now that we cannot name ages after all of the new materials being developed. Aind they are replaced so rapidly that the use of the term "Age" no longer applies.

We are in the midst of rapid political change that may reshape the relationships between government and its research partners in industry and academia. We are all going to have to make adjustments in our professional lives in order to keep pace. With continued pressure to balance the budget, federal research and development (R\&D) spending will, at best, be frozen at current levels for high priority programs which amounts to a $10-15 \%$ cut while other, lower priority programs face deeper cuts on the order of $25-30 \%$ over the next seven years.

I don't have to remind you that your societies have a great deal at stake in these proposals to cut funding and terminate programs. Research cuts affecting the materials sciences come at an especially bad time, given the fact that in many critical areas like nanotechnology, we can only advance so far before we need breakthroughs in materials research.

The federal $R \& D$ cuts will also have another type of effect upon your societies. To the extent that these cuts diminish the attraction of science and engineering as a field of employment, undergraduate students may think twice before pursuing a career in these fields. To the extent that these R\&D cuts, along with cuts in education, affect the viability of graduate programs at universities, you may see fewer scientists and engineers.

We are also seeing many changes in the political process by which we set these policies. A major problem with the process is the widespread ignorance among many members of Congress about government programs and how they work. I was shocked to read recently about an actual quote from a member of Congress who is critical of federal R\&D funding. This unnamed member said that "government should stop supporting scientific research, inasmuch as all of the universities are doing it anyway." That one person in this society, let alone a member of Congress, should have this view of how our science and technology (S\&T) enterprise works is a clear signal of how awry the policy process is.

I am giving you this stark view of reality to motivate you to change your own strategy. You need to organize and use the strength of your membership of the science, engineering, and academic community and of FMS to educate the public and your elected representatives, at all levels, about the importance of the work that you do. Organizations with local chapters or sections can sponsor candidate debates focused on science and engineering issues while retaining your organizations' nonpartisan and nonprofit status. You can be sure that whichever candidate wins will be aware of your issues and the fact that there are a bunch of organized scientists and engineers among their constituency.

You should also develop local, regional, and state summaries on the importance of R\&D programs. This helps make your arguments for support more concrete by being able to show that your city, county, or state depends upon research for jobs, progress, and development. Getting local business organizations involved in this effort helps drive that message home. Using this information with editorial boards help ensure that S\&T issues get local press attention.

There is a range of other actions that can be taken, all with a simple goal of raising your visibility. But this requires a change in attitude on the part of your community. For a long time, the science and engineering disciplines gained stature by being independent observers of the policy process, providing unbiased and dispassionate information. Now that distance from the policy process is dysfunctional as other sectors of society are competing for scarce funding.

I am willing to help in this process. I have been speaking out to science, engineering, and academic groups to get them more deeply involved in political decisions being made. I have also been trying to make my colleagues in Congress more aware of science and engineering constituencies in their districts, and have helped organize an $R \& D$ task force as part of the House Democratic Caucus. I see the development of a lasting political presence for scientists and engineers is the crowning effort of my political service. I hope you will help me meet that goal.

GEORGE E. BROWN, JR.

George E. Brown, Jr. is a U.S. Congressional representative for San Bernardino, California. He is the Ranking Democratic Member of the House Science Committee.

\section{CALLFOR APPLICATIONS}

\section{for the Fifth NSF-Sponsored Materials Chemistry Workshop}

The Fifth NSF-Sponsored Materials Chemistry Workshop will be held October 16-19, 1997, in Pasadena, California. This workshop will be a forum to identify emerging science and technology issues and to promote a dialog among industry, government, and academic scientists. Presentations must not be summaries of completed studies, but rather a discussion of work in progress, emphasizing unanswered questions and providing a vision of directions and opportunities in materials chemistry research. Previous workshops have had topical coverage in areas including progress in materials with engineered fine structures and properties and applications in such areas as surface modification, sensors, information processing, drug delivery, catalysis, electronic and optical components, and energy storage.

For specific guidelines on abstract proposals, contact Seth Marder, California Institute of Technology, 139-74, Pasadena, CA 91125; 818/395-2829; fax 818/449-4159. Tim Swager, Department of Chemistry, Massachusetts Institute of Technology, Building 18-309, Cambridge, MA 02139; 617/2534423; fax 617/253-7929. All applications (an original and four copies) should be addressed to Seth Marder and must be received by June 1, 1997. 


\section{ATTENTION}

MRS Members

\section{Please update your address for the 1997 Membership Directory} (Publication date: August 1997)

1 Check the address label on your copy of the MRS Bulletin.

2 Fill in the form below if you want a different address to be included in the Membership Directory.

\section{Deadline for Directory Listings is May 15, 1997}

To USA Members: Postal automation requires a street address or P.O. Box validated by the U.S. Postal Service. (This is true even for universities.) If you do not know your street address or P.O. Box, please contact your mailroom or your local postmaster.

\section{My Membership Directory address should read as follows:}

Please send my mail to the address at right.

$\square$ Please send my mail to a different different follows below.

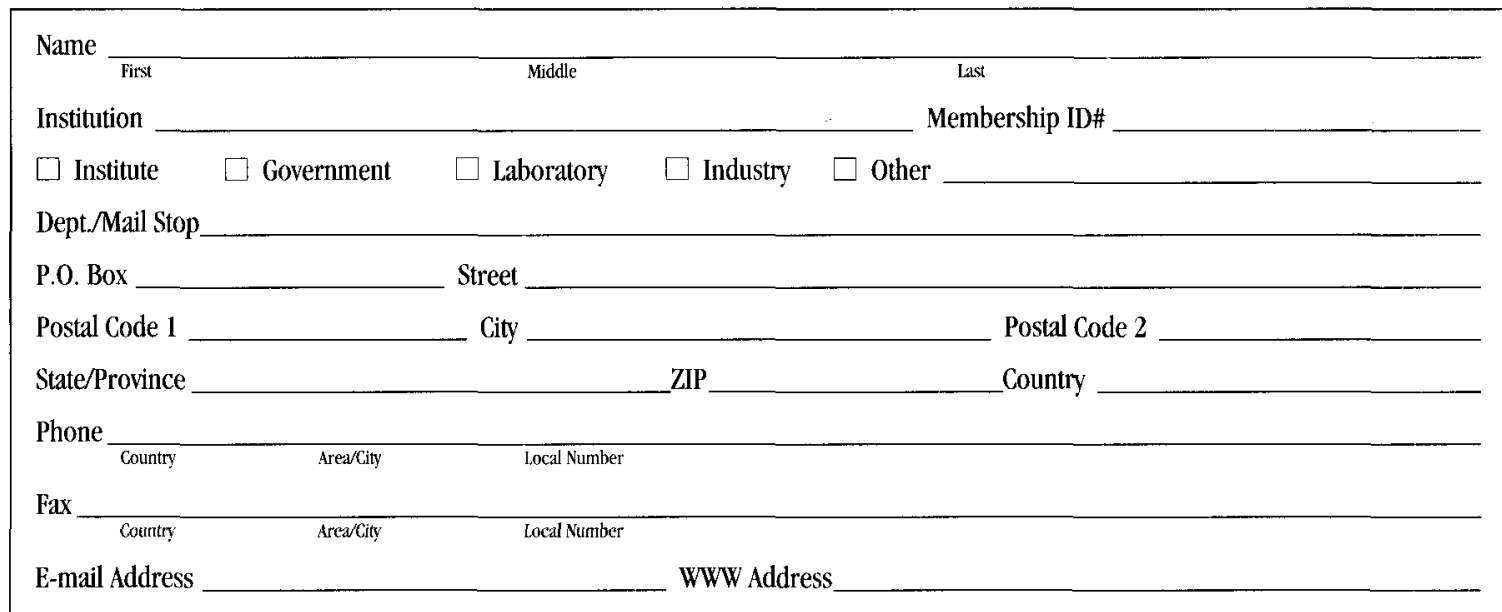

My address for mailings should read as follows:

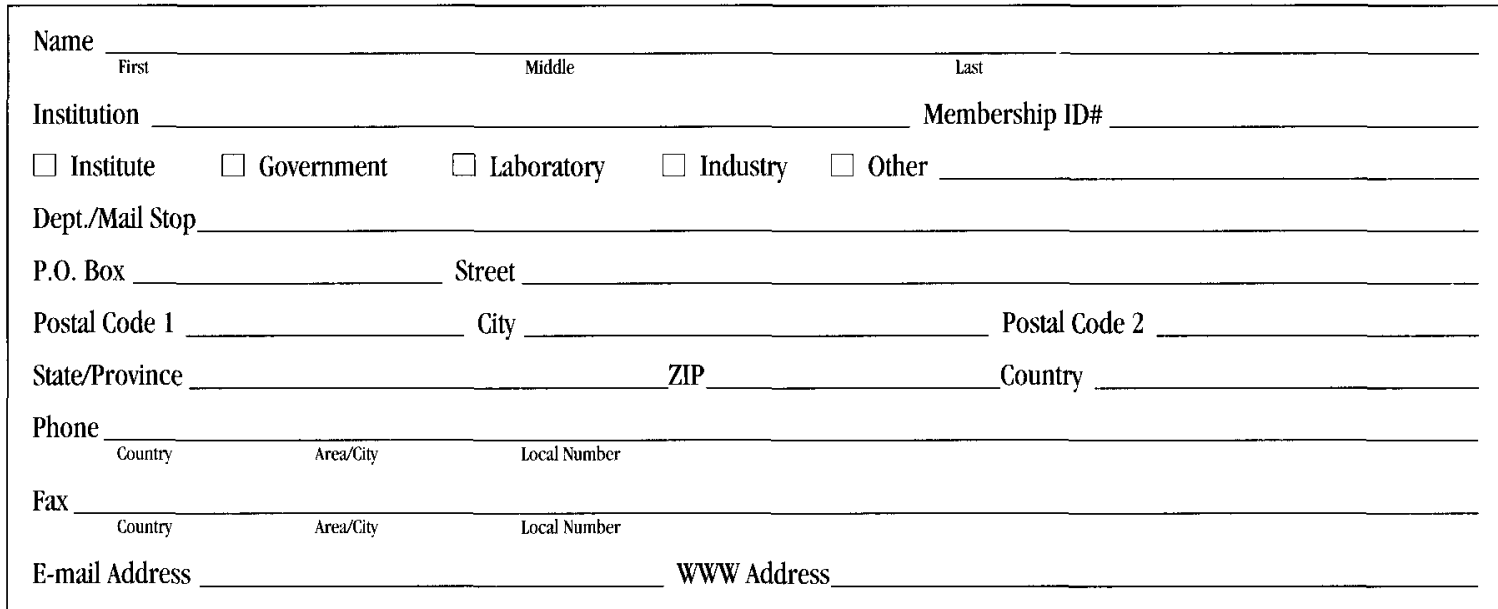

